\title{
Environmental Legislation: A Necessity in Preserving Our Common Biosphere?
}

\author{
J. T. Trevors • M. H. Saier Jr.
}

Published online: 19 January 2007

(C) Springer Science + Business Media B.V. 2007

Unfortunately, many people don't make the correct choices unless regulations have been legislated and enforced. Just imagine how chaotic and insecure our world would be if there were no laws. Why, society as we know it would probably fall apart! We would return to a state comparable to those of the other wild animals (some of which have social structures). This outcome could be expected unless, of course, reason and concern for the common good dominated our egocentric, selfish interests.

It is equally unfortunate that even legislation and enforcement do not always bring about the desired results. This is obvious by the number of crimes committed and the inappropriate punishments provided by the justice system. Also problematic are crimes that are committed that go unpunished because of inadequacies in the legal system. For this reason we might consider the enforcement of laws to be a last resort approach. If people can be encouraged, rewarded or cajoled into making the right choices,

J. T. Trevors $(\bowtie)$

Department of Environmental Biology,

University of Guelph,

Guelph, ON, Canada N1G 2W1

e-mail: jtrevors@uoguelph.ca

\section{H. Saier Jr.}

Division of Biological Sciences, University of California,

San Diego La Jolla, CA, USA

e-mail: saier@biomail.ucsd.edu our world would function optimally with minimal police and military action.

Crimes against our common biosphere are committed regularly. From a legal perspective, these environmental insults may not be crimes. The actions of people who commit them are considered acceptable by some since there are no laws against them. However, their actions have long-term damaging effects on society and the biosphere. To make matters worse, damaging actions may even be encouraged by governments, industries and individuals, usually because of some short-term profit or personal benefit. Examples of actions that are or should be considered crimes include: (1) destruction caused by wars and other military conflicts, (2) unwarranted depletion of non-renewable resources, (3) excessive wastage and pollution, and (4) lifestyles based on consumption instead of conservation. In a democracy, one can even consider ignorance or an attitude of apathy to be damaging, and therefore a moral transgression.

Based on these considerations, we argue that since too many people do not make responsible choices, these choices may in some cases need to be legislated into laws that are enforceable. Examples of suitable legislation could include: restrictions on water consumption, prohibition of vehicles that do not achieve satisfactory efficiency in fuel consumption and restrictions on the use of recreational vehicles generally used as adult toys. Of equal importance, the advertising industry must be encouraged to 
promote responsible lifestyles, and the public must be educated about the necessity to put long-term goals above short-term goals that impact society negatively. Only with an understanding of what is at stake will the proposed legislation stand a chance of being properly received and cooperatively acted upon.

Above all, we need to promote actions that will allow a decrease in the human population. A decrease by several billion will be required to restore sustainability. Since most of the population growth occurs in poor, developing countries, this would involve providing birth control services worldwide, at the expense of the wealthy nations. Encouragement of lifestyles that do not involve procreation (through advertising, propaganda and a system of rewards and punishments) would also help. We need to increase international awareness of the precarious situation that has resulted from our excessive human population. We must encourage participation in population reduction programs and make sure citizens recognize that procreation is a moral issue. Finally, prohibitions against habitual drug users and other people unsuitable for parenthood from having children could be implemented.

In order to parent, it could and maybe should be required that a couple go through qualification testing just as is required for adoption. A primary goal must be to ensure that all children brought into the world will not be hampered by deleterious conditions. Society and the parents must be able to provide loving, lastingly secure environments, or childbirth should be strongly discouraged. Considering the severity of the world's situation, policies such as the one child policy in China might be considered, although numerous available international studies suggest this may not be necessary.

Legislation may be able to ensure the preservation of our world. However, environmental legislation will be difficult to implement at all levels. Too many people are accustomed to acting out of self-interest alone. But enforceable agreements must be in place as soon as possible in order to reverse the head-on collision course that our expanding population is causing. Since migration to a second planet is not possible, international agreements restricting human population growth must be the number one priority. If migration from third world countries to wealthier nations is only possible for some people, then the best approach is to allow the former countries to restrict their populations so the people can benefit from economic advances.

Care must be taken when creating and enforcing laws. Legal procedures could evolve into violations of human rights. However, a lack of restriction leads to starvation, conflicts and suffering, all of which also represent gross violations of basic human rights. Human populations need to be better educated so they can make choices and undertake activities that benefit humanity, not just an individual's life style. If consumers do not purchase fuel-guzzling vehicles, manufacturers will not produce them. Legislative incentives that promote intelligent, meaningful and correct long-term decisions must be encouraged.

We need to hinder the use of inefficient recreational vehicles in favor of bicycles, walking, jogging and sailing. If the latter activities are pursued, the population as a whole will be happier and healthier. The consumer has the power, but not yet the willpower, to ignore consumer-driven lifestyles promoted by the advertising industry. Just because someone can afford to buy something, does not mean that the object is needed or even desired. The wealthy have much to learn before they can achieve long-term happiness. Even they need to consider the futures of their progeny. Money will not protect anyone from the ills resulting from human overpopulation and global warming.

We suspect that some businesses will not willingly conform to an altruistic plan. Why should they? Their purpose is to make immediate profits, and a program such as the one we propose will at best yield longterm profits. For these reasons, the directors who manage the companies must be provided with sufficient incentives and directives so that we can all reside in, protect and prosper in our common, shared biosphere.

Does all of this sound like a lot of hot air and idealism? Perhaps, but the consequences will be dire if proper action is not taken. And implementation may not be as difficult as it seems. We need to be educated and educate our friends and associates so that we all can act logically. Only by so doing will we ensure that future generations will be subjected to minimal suffering. Legislation and international agreements may or may not prove to be necessary to protect and maintain our biosphere, but the greedy side of humankind must somehow be suppressed. More humans, more consumption and more irresponsible 
economic growth do not promote a future of quality life. And a future of suffering and misery is no future at all.

In his famous essay, "The Tragedy of the Commons," the great human ecologist and educator, Garrett Hardin, wrote "Unlimited freedom of reproduction suffocates all other goods of life! To couple the concept of freedom to breed with the belief that everyone born has an equal right to the commons is to lock the world into a tragic course of action." He goes on to claim that "The only way we can preserve and nurture other more precious freedoms is by relinquishing the freedom to breed." He quotes Hegel who said, "Freedom is the recognition of necessity." And necessity is the best teacher!

We are not certain that Hardin was entirely correct in his views and proposal. Perhaps we do not need to legislate birth restriction. What we need to guarantee, at least initially, is the right of all women to choose their reproductive fulfillment. Hundreds of studies conducted worldwide indicate that when women make the decisions and have free access to birth control methods, fertility rates fall dramatically. These rates decline to the replacement level or lower as has occurred in almost all developed nations. Empowered women everywhere choose to restrict their family sizes regardless of economic level and education. It therefore seems to us that the first step in achieving a sustainable world is to ensure that women have the right to restrict their family sizes in accordance with their preferences. If this doesn't suffice in bringing our population down to sustainable levels, or if it doesn't happen rapidly enough to prevent the expansion of suffering, then other measures would be justified.

Numerous cross-culture studies have demonstrated what the incorrect pathway is. Programs of "abstinence only" simply don't work. Misleading religious dogma must be counteracted with logic, and religious leaders must assume responsibility. The people must demand it! You must demand it! I must demand it! WE ALL must demand it! Back to reality. The real question is: can we count on human populations to understand the consequences of their actions and act accordingly? Considering the darker side of human nature, the lust for power, the greed for wealth and possession, and the irrationality of mystical beliefs, the answer to this question is uncertain. Only time will tell. But we must do all we can, and the time is now. 